\title{
Differentiation of Hamster Liver Oval Cell Following Clonorchis sinensis Infection
}

\author{
Byung-Il YOON ${ }^{1)}$, Su-Youn JUNG ${ }^{2}$, Kwon HUR ${ }^{2)}$, Jae-Hyun LEE ${ }^{4)}$, Kyung-Hwan JOO ${ }^{5)}$, Yong-Soon LEE ${ }^{3)}$ and \\ Dae-Yong $\mathrm{KIM}^{2} *$ \\ ${ }^{1)}$ Division of Cellular and Molecular Toxicology, National Institute of Health Sciences, Tokyo 158-8501, Japan, ${ }^{2)}$ Departments of \\ Veterinary Pathology and ${ }^{3)}$ Public Health, College of Veterinary Medicine, Seoul National University, Suwon, 441-744, ${ }^{4)}$ Experimental \\ Pathology Laboratory, Korea Cancer Center Hospital, Seoul and ${ }^{5)}$ Department of Parasitology, College of Medicine, Korea University, \\ Seoul, Korea
}

(Received 12 April 2000/Accepted 26 October 2000)

ABSTRACT. Oval cells which appear in the liver after hepatic injuries are suspected to be progenitor cells for both hepatocytes and bile duct cells. Oval cell isolated from the livers of the hamsters treated with diethylnitrosamine and 2-acetylaminofluorene and infected with Clonorchis sinensis (CS), cultured for 2 weeks and evaluated for differentiation and plasticity by electron microscopy and immunohistochemistry. In the CS-uninfected group, glycogen granules and peroxisomes were noted in the cells that were cultured for 2 weeks. Starting at 1 week postculture, immunoreactivity of the cells to cytokeratin 19 markedly decreased but that to albumin and alpha-fetoprotein gradually increased. This means that oval cells isolated from hamsters that were not infected with CS differentiated toward hepatocyte lineage. However, in the CS-infected group, cultured cells contained numerous rough endoplasmic reticulum and showed immunoreactivity that was generally in reverse to that of CS-uninfected group, meaning that cells isolated following CS infection were primed by CS and differentiated toward bile duct cell lineage. The results of this study suggested that oval cells are indeed bipolar progenitor cells for hepatocytes and bile duct cells and can differentiate toward either lineage depending upon the priming factor. KEY WORDS: 2-acetylaminofluorene, Clonorchis sinensis, diethylnitrosamine, hamster, oval cell.

J. Vet. Med. Sci. 62(12): 1303-1310, 2000

Proliferation of small cells, which are also called as oval cells on the basis of their morphology, is the first cellular changes noted in the livers of different experimental animals when they are treated with various carcinogens $[1,2,4,10$, 13, 17]. This population of cells first appears intraportally and then extends into the periportal zone, where they may constitute a majority of the liver cellular elements, particularly in rats and hamsters fed choline deficient diet or given hepatocarcinogens $[2,6,9,17,23,26]$. Oval cells seen in the hamster are similar to those in rats morphologically, cytochemically and immunocytochemically [8, 26]. Recently, we have isolated highly purified oval cells from the hamster livers treated with diethylnitrosamine (DEN) and 2-acetylaminofluorene (2-AAF) and fed a choline deficient diet [26]. These hamster oval cells have ovoid or irregular nuclei, a high N/C ratio and scant cytoplasmic organelles, and express different degrees of gammaglutamyltranspeptidase (GGT), cytokeratin 19 (CK19), alpha-fetoprotein (AFP) and albumin [26].

A feature of oval cells is their apparent ability to differentiate into either hepatocytes or biliary cells depending on environmental situation or regulatory factors $[2,6,7,9,13$, 20]. In addition, they are believed to be the cells of origin of hepatocellular carcinomas (HCC) and cholangiocellular carcinomas (CCC) $[15,16]$. Cultured rat oval cells express both hepatocyte markers (AFP, albumin) and biliary markers (GGT, CK19) [7, 11, 18, 19, 25] and a transformed oval cell lines, when transplanted to syngeneic recipients, devel-

\footnotetext{
* Correspondence to: Kim, D.-Y., Department of Veterinary Pathology, College of Veterinary Medicine, Seoul National University, Suwon, 441-744, Korea.
}

ops into HCC, CCC or anaplastic tumors [3, 22, 24, 27].

Clonorchis sinensis (CS) infection combined with hepatocarcinogen treatment results in marked oval cell proliferation and atypical bile duct hyperplasia followed by development of CCC in hamsters, implying that CS infection causes the facultative bipotential oval cells to differentiate into precursors of CCC [8]. However, direct analysis of the differentiation and plasticity of oval cells in hamsters has not been critically performed. Therefore, the cellular origin of CCC observed in carcinogen-treated hamster livers and atypical bile ductules appearing in the carcinogentreated and CS-infected hamster livers is still not clearly understood, although it is assumed to be derived from oval cells based on the in vivo results.

In the present study, phenotypic changes of the oval cells isolated from hamsters infected or not infected with CS are characterized during short-term culture to address the relationship between CS infection and differentiation of oval cells in hamsters.

\section{MATERIALS AND METHODS}

Animals, experimental protocol and histology: Male, Syrian golden hamsters (55 60 g body weight) were housed in polycarbonate cages and maintained in temperature $(21 \pm$ $\left.2{ }^{\circ} \mathrm{C}\right)$ and humidity $(50 \pm 3 \%)$ controlled air-filtered rearing system (Daejong Co., Korea) with a $12 \mathrm{hr}$ light/dark illumination cycle. The hamsters were used after 1 week acclimatization to the housing environment. To induce the oval cells, $0.005 \%$ DEN (Sigma Co., U.S.A.) was given to the animals in drinking water for 2 weeks followed by 1 week 
recovery period and then $1 \% 2-\mathrm{AAF}$ (Sigma Co., U.S.A.) in corn oil was administered $0.1 \mathrm{~m} / /$ day orally for another 2 weeks under choline deficient diet. During 2-week exposure to 2-AAF, the hamsters were divided into two groups and kept with or without CS infection, and then used for oval cell isolation and in vitro cultivation. In addition, to compare the differentiation pattern of isolated oval cells during in vitro culture to that of in vivo situation, after administering 2-AAF for 2 weeks with or without CS infection, the hamsters were maintained another 2 weeks under normal diet. At the end of the experiment (7-week postinitiation and 4-week post-CS-infection), the livers of hamsters that were CS-infected or CS-uninfected were histologically compared. For histopathology, several sections of the livers were fixed in $10 \%$ phosphate buffered neutral formalin, routinely processed, embedded in paraffin and stained with hematoxylin and eosin (H\&E). In each group, 5 hamsters were used for oval cell isolation and 3 hamsters were used for histopathological examination.

Preparation of Clonorchis sinensis metacercariae: The metacercariae of CS were obtained from the flesh of fresh water fish (Pseudorasbora parva) captured in Nakdong River basin, an endemic area of liver fluke infection in Korea. The whole flesh of the fish was digested for $5 \mathrm{hr}$ at $37^{\circ} \mathrm{C}$ with artificial gastric juice $(0.6 \%$ pepsin in $0.7 \% \mathrm{HCl}$ solution, $\mathrm{pH} 2.0)$. The digested content was then filtered through $0.147 \mathrm{~mm}$ diameter sieve and washed thoroughly several times with physiologic saline. Metacercariae were selected under a stereomicroscope and kept at $4{ }^{\circ} \mathrm{C}$ in physiologic saline until infection.

Isolation and culture of oval cells: After necropsy, only the livers showing grossly pale and granular appearance indicative of successful oval cell induction were used for oval cell isolation. Oval cell isolation was performed by the method of Pack et al. [11] with minor modification. The liver was initially perfused in situ through the portal vein for 5 min with oxygenated, calcium-free Hank's balanced salt solution (with $20 \mathrm{mM}$ HEPES and $4 \mathrm{mM}$ EGTA, without bicarbonate, $\mathrm{pH}$ 7.4) by a noncirculatory way followed by perfusion with oxygenated, calcium-supplemented Hank's balanced salt solution containing $0.1 \% \mathrm{wt} / \mathrm{v}$ collagenase type I (Sigma Co., U.S.A.) for $10 \mathrm{~min}$ at an infusion rate of $10 \mathrm{ml} / \mathrm{min}$ at $37^{\circ} \mathrm{C}$. After perfusion, the excised liver was washed thoroughly several times with $0.1 \mathrm{M}$ PBS containing $1 \%$ penicillin/streptomycin (Sigma Co., U.S.A.) and then Glisson's capsule was removed. The liver was minced in $25 \mathrm{ml}$ of Dulbecco's minimum essential medium (DMEM) (Gibco, Germany) containing $0.1 \% \mathrm{wt} / \mathrm{v}$ collagenase type I, 0.004\% wt/v DNase (Sigma Co., U.S.A.) and $0.1 \% \mathrm{wt} / \mathrm{v}$ pronase (Sigma Co., U.S.A.) and incubated immediately twice for $20 \mathrm{~min}$ at $37^{\circ} \mathrm{C}$ with vigorous shaking. After each incubation, the supernatant was decanted and filtered through $100 \mu \mathrm{m}$ mesh and then cold DMEM with $3 \% \mathrm{v} / \mathrm{v}$ fetal bovine serum (Sigma, U.S.A.) was added and centrifuged at $400 \mathrm{~g}$ for $5 \mathrm{~min}$ at $4{ }^{\circ} \mathrm{C}$. The pellet was resuspended with Gey's balanced salt solution (GBSS, Gibco, Germany) and recentrifuged at $400 \mathrm{~g}$ for $5 \mathrm{~min}$ at 4
${ }^{\circ} \mathrm{C}$. In order to eliminate the dead parenchymal cells and red blood cells and to obtain only non-parenchymal cells, a density gradient centrifugation in Nycodenze (Sigma Co., U.S.A.) was performed. The pellet was resuspended with GBSS in a final volume of $11 \mathrm{~m} l$ and mixed gently with 14 $\mathrm{m} l$ of the $28.7 \% \mathrm{w} / \mathrm{v}$ Nycodenze solution. This layer was covered with $2 \mathrm{ml}$ GBSS. After centrifugation at $400 \mathrm{~g}$ for $15 \mathrm{~min}$ at $4^{\circ} \mathrm{C}$, highly enriched non-parenchymal fraction was removed and centrifuged at $400 \mathrm{~g}$ for $5 \mathrm{~min}$ at $4^{\circ} \mathrm{C}$. After resuspending the pellet with $5 \mathrm{ml}$ of elutriation medium (DMEM containing 0.004\% w/v DNase and 3\% v/ $\mathrm{v}$ fetal bovine serum), centrifugal elutriation was performed to further purify the oval cells from the non-parenchymal cell suspension. A JE-5.0 elutriation centrifuge rotor with a Sanderson seperation chamber (Beckman Instruments) was used in a J-6 M/I centrifuge (Beckman instrument) set at $2,500 \mathrm{rpm}$ and $10^{\circ} \mathrm{C}$. The cell suspension was loaded in the elutriation system and the oval cell fraction was obtained by using flow rate of $32 \mathrm{ml} / \mathrm{min}$ as previously determined [26]. The cell viability was estimated by trypan blue and then the isolated oval cells were plated in 24- or 48-well plate and cultured at $37^{\circ} \mathrm{C}$ in a humidified atmosphere of $5 \% \mathrm{CO}_{2}$. The culture medium used for oval cell culture was DMEM:F10(1:1) supplemented with $10 \% \mathrm{v} / \mathrm{v}$ fetal bovine serum, $0.5 \mu \mathrm{g} / \mathrm{m} l$ hydrocortisone (Sigma Co., U.S.A.), $1 \mu \mathrm{g} /$ $\mathrm{m} l$ insulin and $1 \% \mathrm{v} / \mathrm{v}$ penicillin/streptomycin. The culture medium was changed every 3-4 days.

Cytochemistry: Cell smears from freshly isolated oval cells and the oval cells cultured for 4,7 , or 14 days were fixed in cold acetone for $10 \mathrm{sec}$ and stained according to the method of Rutenberg et al. [12] to detect GGT activity.

Immunocytochemistry: Immunostaining for CK19, albumin, and AFP was performed on the cell smears from freshly isolated oval cells and the oval cells cultured for 4,7 or 14 days by standard avidin-biotin-immunoperoxidase method (Vector Lab., U.S.A.). After quenching the endogenous peroxidase activity and treating the slides with normal horse serum to block non-specific binding, the slides were incubated at $4{ }^{\circ} \mathrm{C}$ overnight with primary antibodies to CK19 (Novocastra, U.S.A.), albumin (Biogenex, U.S.A.) and AFP (a gift from Dr. Sell at Albany Medical College, U.S.A.) at 1:100, 1:100 and 1:200 dilution, respectively. 3'-3'-diaminobenzidine was used as the chromogen to visualize the peroxidase binding sites. For negative control, primary antibodies were omitted and only the primary antibody dilution buffer was applied. Isolated and smeared rat oval cells using centrifugal elutriation were used as positive control. Immunoreactivity of each slide to CK19, albumin and AFP was determined by counting approximately 500 cells per slide. The immunostaining for each antibody was performed five times at each time point, and the results were presented as mean $+/$ - SD.

Electron microscopy: The oval cell pellets were fixed with $1.6 \%$ glutaraldehyde in Sorenson's sodium phosphate buffer $(2.78 \%$ monohydrate sodium phosphate monobasic, $2.849 \%$ anhydrous sodium phosphate dibasic). After washing 3 times in $0.01 \mathrm{M}$ phosphate buffer, the cells were post- 


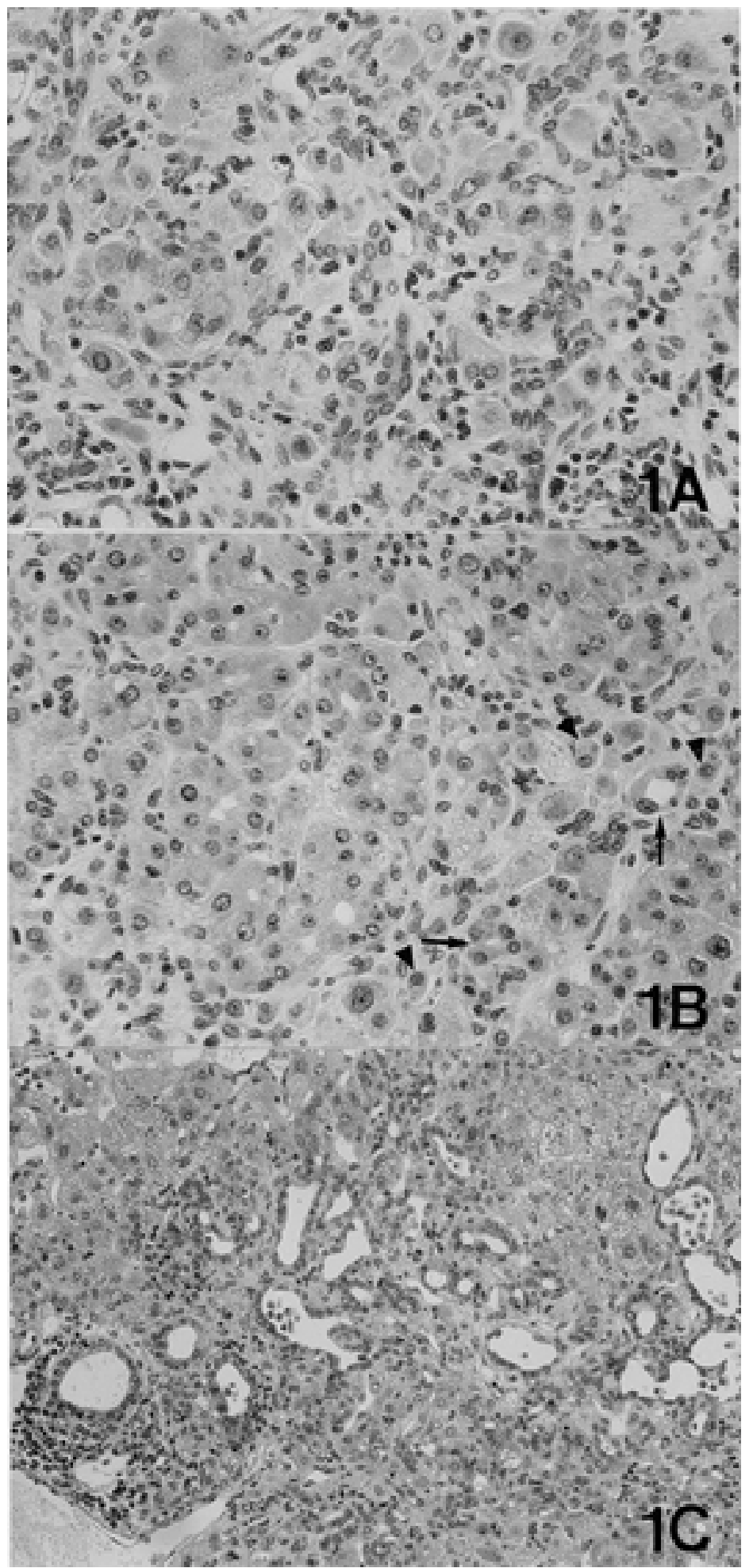

Fig. 1. Morphologic changes in Clonorchis sinensis-infected and uninfected hamster livers. (A) Liver of the hamster administered with $0.005 \% \mathrm{DEN}$ for 2 weeks followed by 1 week recovery period and 1 week 2-AAF administration (4-week postinitiation). Massive proliferation of the oval cells in the portal spaces was observed throughout the section. (B) CS-uninfected group (7-week postinitiation). Proliferated periportal oval cells differentiated into hepatocellular lineage. Note "small hepatocytes"(arrow heads), ductules surrounded by immature hepatocytes ("ductular hepatocytes") and oval cells (arrows). (C) CS-infected group (7-week postinitiation and 4 weeks after CS infection). Bile ductular structures were frequently noted in the portal and periportal areas. H \& E; (A), (B) and (C) $\times 200$. 
fixed in $1 \% \mathrm{O}_{\mathrm{S}} \mathrm{O}_{4}$ for 30 min, washed 3 times in $0.01 \mathrm{M} \mathrm{PB}$, dehydrated in graded ethanol and propylene oxide, and embedded in Epon. Ultrathin sections were stained with uranyl acetate and lead citrate and examined under Philips CM12 electron microscope.

\section{RESULTS}

Histology: After DEN and 2-AAF treatment under choline deficient diet, oval cells proliferated in the portal spaces in rows or clusters along the plates of hepatocytes or formed duct-like structures outside of the portal spaces in hamster livers of both groups (Fig. 1A). However, after 2 weeks of normal diet without CS infection, the oval cells protruded into midzonal area and most of the oval cells differentiated into hepatocyte lineage (Fig. 1B). On the contrary, bile ductular structures which were assumed to be derived from the induced oval cells were frequently observed in the CSinfected hamster livers after 2-week postinfection (Fig. 1C).

Oval cells isolated from livers of hamsters not infected with $C$. sinensis: In all cases, the viability of isolated oval cells was $>95 \%$ as judged by trypan bule dye exclusion test, and the cells were principally small having a mean diameter of $10.71 \mu \mathrm{m}$. Electron microscopically, the freshly isolated oval cells had ovoid or irregular nuclei, variable amounts of condensed chromatin, high nucleus/cytoplasm ratios and very few cytoplasmic organelles (Fig. 2A). During their culture for 4 to 7 days, there were no marked changes in morphology except for slight increases in the cell size and numbers of mitochondria and rough endoplasmic reticulum (RER) in the cytoplasm. In oval cells cultured for 14 days, however, cytoplasmic organelles with central crystalline core and the size (approximately $0.5 \mu \mathrm{m}$ ) compatible with peroxisomes and clusters of glycogen granules were noted (Figs. 2B, C, D). Cytochemical and immunocytochemical examinations of freshly isolated oval cells showed that 30.2 $\pm 1.7 \%$ of the cells were GGT positive (Fig. 3A), $81.7 \pm$ $3.1 \%$ were CK 19 positive (Fig. $4 \mathrm{~A}$ ), $62.0 \pm 1.2 \%$ were albumin positive (Fig. 5A) and $25.6 \pm 2.7 \%$ were AFP positive (Fig. 6A). During their culture for 2 weeks, there was a marked change in the immunostaining pattern of CK19. The percentage of cells stained positive to CK19 decreased markedly from $81.7 \pm 3.1 \%$ to $11.6 \pm 1.4 \%$ on 7 -day postculture (Fig. 4B) and remained low until 14-day postculture. GGT reactivity also gradually decreased during 14-day culture from $30.2 \pm 1.7 \%$ to $17.6 \pm 1.7 \%$ (Fig. $3 \mathrm{~B}$ ). On the contrary, immunoreactivity to albumin and AFP gradually increased during 14-day culture from $62.0 \pm 1.2 \%$ to $75.3 \pm$ $2.1 \%$ (Fig. 5B) and $25.6 \pm 2.7 \%$ to $33.4 \pm 1.8 \%$ (Fig. 6B), respectively. The phenotypic changes during their culture are summarized in Fig. 7.

Oval cells isolated from livers of hamsters infected with C. sinensis: The cell population of oval cell fraction isolated from CS-infected hamster livers also showed viability of $>95 \%$, and their mean cell size and electron microscopic appearances were similar to those isolated from uninfected hamster livers. Electron microscopically, there were no marked changes in morphology during the culture for 4 to 7 days except for a slight increase in cell size. On 14-day postculture, however, there were significant increases in the numbers of mitochondria and RER, especially RER in the cytoplasm (Figs. 2E, F). Peroxisomes or glycogen granules seen in the oval cells cultured from CS-uninfected hamster livers were not found during their culture. In cytochemical and immunocytochemical examinations, $31.2 \pm 1.6 \%$ of the freshly isolated cells were GGT positive, $84.8 \pm 1.8 \%$ were CK 19 positive, $58.1 \pm 3.8 \%$ were albumin positive and 23.6 $\pm 2.9 \%$ were AFP positive. Compared to the oval cells isolated freshly from CS-uninfected hamster livers, there were no notable differences in the cytochemical and immunocytochemical phenotypes of these cells. However, immunoreactivities of the cells isolated from CS-infected group to CK19 remained greater than $80 \%$ during their 14-day culture (Fig. 4C). The percentage of cells expressing GGT activity showed the tendency to increase during the culture (Fig. 3C). In addition, the percentage of cells stained positive for either albumin or AFP decreased from $58.1 \pm 3.8 \%$ to $33.8 \pm 2.8 \%$ and $23.6 \pm 2.9 \%$ to $8.9 \pm 1.5 \%$, respectively, during their culture (Figs. 5C, 6C). The phenotypic changes during the culture of oval cells from CS-infected hamster livers are summarized in Fig. 8.

\section{DISCUSSION}

In the present study, differentiation and plasticity of the hamster oval cells were studied by comparing the phenotypic changes of the isolated oval cells between CS-infected and CS-uninfected preneoplastic hamster livers using EM, cytochemistry and immunocytochemistry during their culture for 2 weeks. Morphologically, the oval cells isolated from chemically treated and CS-uninfected hamster livers were similar to those isolated previously from rats fed choline deficient diet containing DL-ethionine [26]. In CSuninfected group, we could find marked decreases of CK 19 expression and GGT reactivity during culture, whereas albumin and AFP immunoreactivity gradually increased (Fig. 7). In addition, glycogen granules and peroxisomes were noted in the cytoplasm of the oval cells cultured for 2 weeks (Figs. 2C, D). These morphological changes, together with the results of cytochemistry and immunocytochemistry, suggest that the oval cells isolated under this protocol commit to develop into hepatocyte lineage rather than biliary lineage. On the other hand, in the oval cells from chemically treated and CS-infected hamster livers, we could not find any morphological changes that indicate differentiation into hepatocyte lineage during the 2-week culture. On the contrary, the phenotypic changes of the oval cells from CS-infected hamster livers were suggestive of differentiation toward biliary lineage as shown by gradual increases of GGT reactivity and CK19 expression and a marked decrease of albumin (Fig. 8). The differentiation patterns of the oval cells were also supported by the histological findings of the hamster livers from the two groups. Immature hapatocytes such as "ductular hepatocytes" and/ 

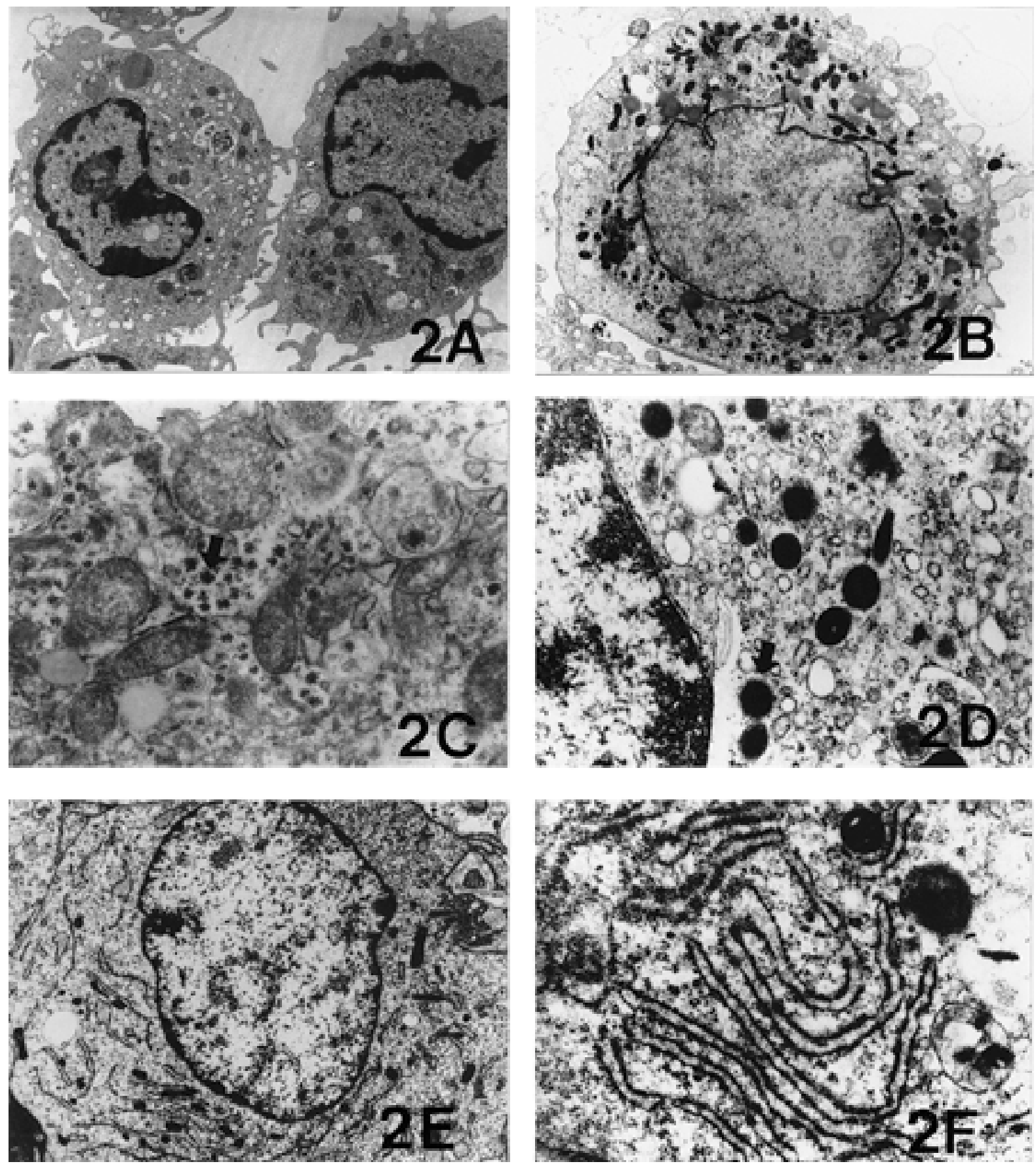

Fig. 2. (A) Electron micrograph of freshly isolated oval cells. The oval cells have ovoid nuclei, high nucleus/cytoplasm ratios, a few small and round mitochondria and scant rough endoplasmic reticulum in the cytoplasm. (B D) Electron micrographs of CS-uninfected oval cells cultured for 7 days. (B) Note the increased mitochondria in the cytoplasm. (C) Note glycogen granules in the cytoplasm (arrow). (D) Note increases of mitochondria and peoxisomes (arrow) in the cytoplasm. (E, F) Electron micrographs of CS-infected oval cells Cultured for 7 days. (E) Note a marked increase of rough endoplasmic reticulum in the cytoplasm. (F) Higher magnification of E. Uranyl acetate and lead citrate. (A) $\times 2,400,(B) \times 5,400,(C) \times 26,400,(D) \times 23,000,(E) \times 6,300,(F) \times 28,900$.

or "small hepatocytes" were common in the liver sections of CS-uninfected hamsters after inducing massive oval cells by DEN and 2-AAF treatment with a choline deficient diet fol- lowed by feeding a normal diet, whereas hyperplastic bile ductules were frequently observed in the livers from the similarly treated CS-infected hamsters (Figs. 1B, C). 

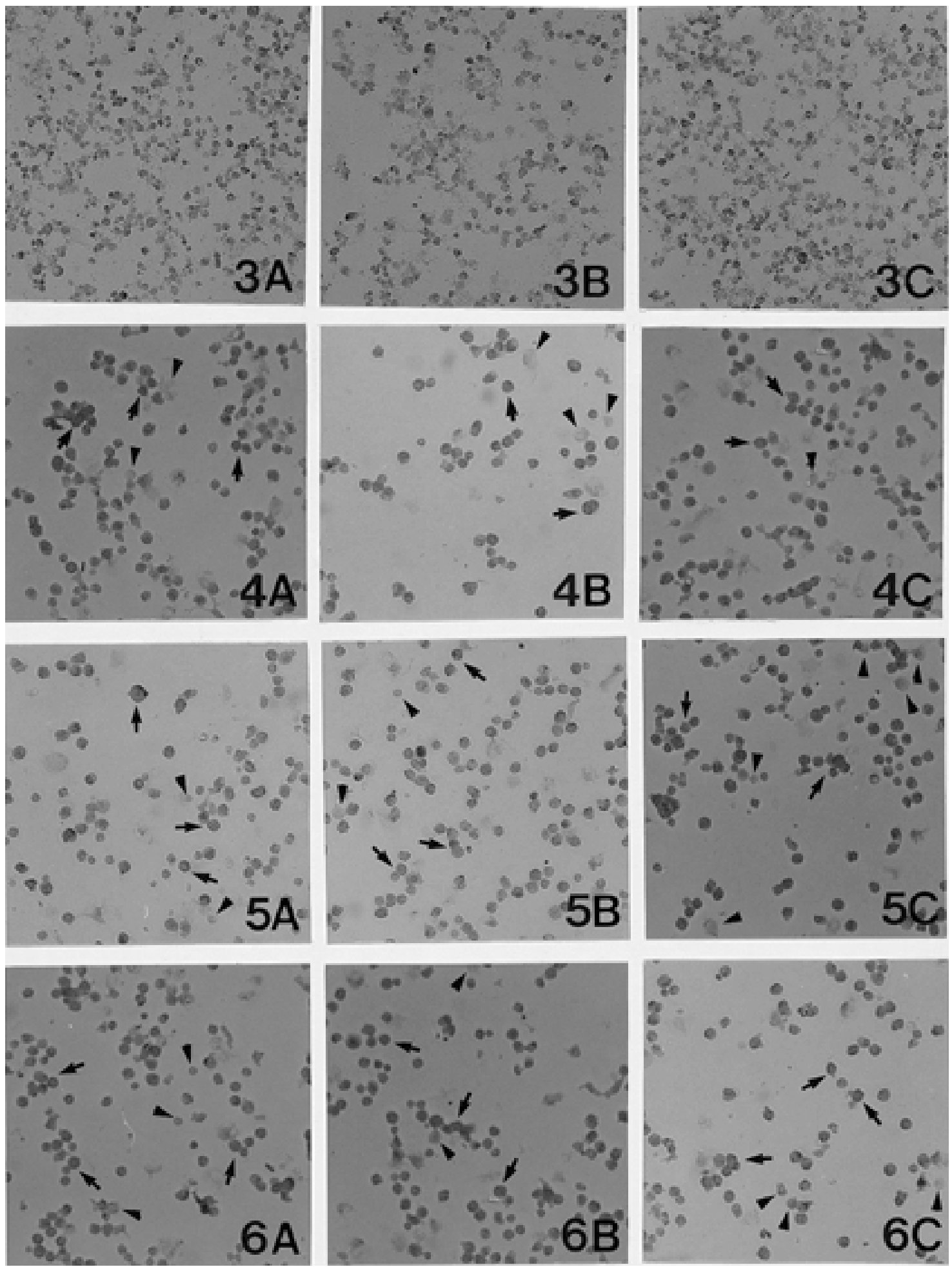

Therefore, in our study, the differentiation of oval cells was affected by CS infection, implying that CS infection had an effect on the differentiation of oval cells. It was assumed that CS infection might inhibit the differentiation of oval cells to hepatocytes, and/or drive facultative bipo- tential oval cells to differentiate toward biliary cell lineage by unknown mechanism.

In the hamster CCC model in which livers are subjected to chemical induction of oval cells followed by CS infection, hyperplasia of atypical bile ductules is a prominent fea- 
CS uninfected group

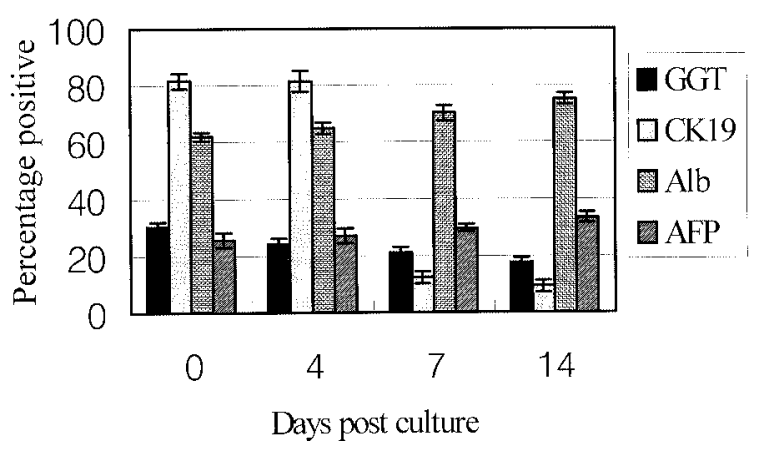

Fig. 7. Phenotypic changes of the cultured oval cells isolated from the livers of Clonorchis sinensis-uninfected hamsters. In freshly isolated oval cells, percentages of positve cells for biliary cell markers, GGT activity and CK19, were $30.2 \pm 1.7 \%$ and $81.7 \pm 2.7 \%$, respectively, and those for hepatocellular markers, albumin and AFP, were $62.0 \pm 1.5 \%$ and $25.6 \pm$ $2.7 \%$, respectively.

ture observed prior to the development of CCC [8]. However, the cellular origin of CCC and atypical bile ductules is still not clearly understood or directly proven, although it is assumed to be derived from oval cells based on the in vivo results [8]. Our results suggest that, at least in the hamster CCC model, the atypical bile ductules that appear prior to CCC development are derived from the oval cells. In our study, the oval cells freshly isolated at the early stage of the hamster CCC model not only showed dual characteristics of hepatocytes and biliary cells but also expressed a fetal hepatocytic marker, which implied that the oval cells were progeny of liver stem cells. The oval cells had the characteristics distinguishable from the hyperplastic bile ductule cells that develop after biliary ligation or treatment with 4,4'-diaminodiphenylmethane $[5,14,21]$. In addition, the oval cells, during their culture, showed the tendency to differentiate toward biliary lineage. Several studies also demonstrated that transformed rat oval cell lines were capable of developing CCC as well as HCC when transplanted into nude mice or syngeneic recipients $[3,22,24,27]$. The results of these studies well support the concept of stem cell origin of CCC $[15,16]$.

Since the culture period was too short, the ultimate fate of

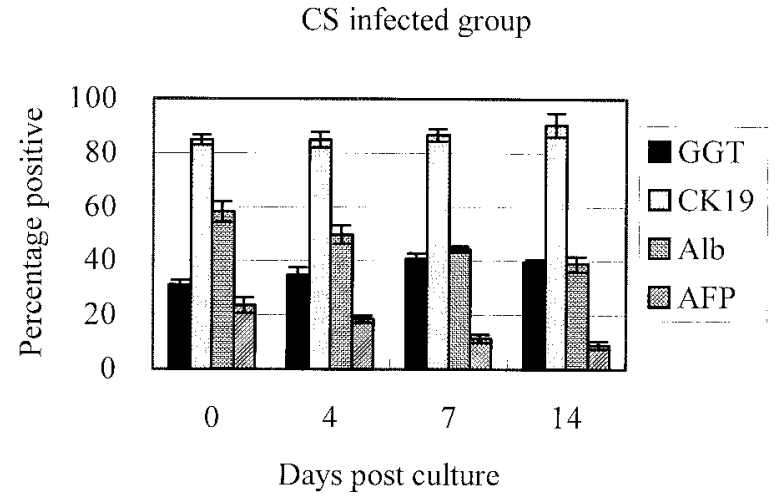

Fig. 8. Phenotypic changes of the cultured oval cells isolated from the livers of Clonorchis sinensis-infected hamsters. In freshly isolated oval cells, percentage of positive cells were $31.2 \pm$ $1.6 \%$ for GGT activity, $84.8 \pm 1.8 \%$ for CK19, $58.1 \pm 3.8 \%$ for albumin, and $23.6 \pm 2.9 \%$ for AFP. During culture for 14 days, positivity for biliary cell markers gradually increased whereas positivity for hepatocellular marker decreased.

oval cells isolated from CS-uninfected or CS-infected livers still remains uncertain. However, our study strongly suggests that CS infection has an important effect on the direction of differentiation of facultative oval cells, and drives them to differentiate into biliary cells that finally could develop into CCC, even if the definite outcome remains to be determined. In this hypothesis, many factors in association with parasite infection should be considered including secretory or excretory products from the worms or eggs and oxygenous or nitrous free radicals or growth factors released from inflammatory cells following CS infection. Further studies and long term culture are in progress to elucidate the regulatory mechanism involving the differentiation of oval cells into CCC during CS infection.

ACKNOWLEDGEMENT. The authors wish to acknowledge the financial support of the Korea Research Foundation made in the program year of 1997.

\section{REFERENCES}

1. Alpini, G., Aragona, E., Dabeva, M., Salvi, R., Shafritz, D. A. and Tavoloni, N. 1992. Distribution of albumin and alpha-feto-

Fig. 3. Cytochemistry of smeared oval cells. Approximately 30\% of freshly isolated oval cells (A) were positive for GGT activity. After culture for 14 days, the percentage of CS-uninfected oval cells positive for GGT (B) decreased while that of CS-infected oval cells (C) moderately increased. $\times 200$.

Fig. 4. CK19 immunostaining of smeared oval cells (arrows, positive; arrowheads, negative). (A) Freshly isolated oval cells. Most of cells reacted for CK19. (B) CS-uninfected oval cells cultured for 14 days. Note marked decrease of positivity for CK19. (C) CS-infected oval cells cultured for 14 days. In contrast to CS-uninfected oval cells, positivity for CK19 moderately increased. Avidin-biotin-peroxidasecomplex method. $\times 400$.

Fig. 5. Albumin immunostaining of smeared oval cells (arrows, positive; arrowheads, negative). Approximately $60 \%$ of freshly isolated oval cells (A) positively reacted for albumin. After culture for 14 days, percentage of CS-uninfected oval cells positive for albumin (B) moderately increased while that of CS-infected oval cells(C) decreased. Avidin-biotin-peroxidase-complex method. $\times 400$

Fig. 6. AFP immunostaining of smeared oval cells (arrows, positive; arrowheads, negative). Approximately $20 \%$ of freshly isolated oval cells (A) positively reacted for AFP. After culture for 14 days, percentage of CS-uninfected oval cells positive for AFP (B) moderately increased while that of CS-infected oval cells(C) decreased. Avidin-biotin-peroxidase-complex method. $\times 400$ 
protein mRNA in normal, hyperplastic, and preneoplastic rat liver. Am. J. Pathol. 141: 623-632.

2. Anikumar, T. V., Golding M., Edwards, R. J., Lalani, E-N, Sarraf, C. E. and Alison, M. R. 1995. The resistant hepatocyte model of carcinogenesis in the rat: the apparent independent development of oval cell proliferation and early nodules. Carcinogenesis 16: 845-853.

3. Braun, L., Goyette, M., Yaswen, P., Thompson, N. L. and Fausto, N. 1987. Growth in culture and tumorigenicity after transfection with the ras oncogene of liver epithelial cells from carcinogen-treated rats. Cancer Res. 47: 4116-4124.

4. Evarts, R. P., Nagy, P., Nakatsukasa, H., Marsden, E. and Thorgeirsson, S. S. 1989. In vivo differentiation of rat liver oval cells into hepatocytes. Cancer Res. 49: 1541-1547.

5. Gall, J. A. M. and Bhathal, P. S. 1990. Origin and involution of hyperplastic bile ductules following total biliary obstruction. Liver 10: 106-115.

6. Germain, L., Goyette, R. and Marceau, N. 1985. Differential cytokeratin and $\alpha$-fetoprotein expression in morphologically distinct epithelial cells emerging at the early stage of rat hepatocarcinogenesis. Cancer Res. 45: 673-681.

7. Germain, L., Noël, M., Gourdeau, H. and Marceau, N. 1988. Promotion of growth and differentiation of rat ductular oval cells in primary culture. Cancer Res. 48: 368-378.

8. Lee, J.-H., Rim, H.-J. and Sell, S. 1997. Heterogeneity of the "oval-cell" response in the hamster liver during cholangiocarcinogenesis following Clonorchis sinensis infection and dimethylnitrosamine treatment. J. Hepatol. 26: 1313-1323.

9. Lemire, J. M., Shiojiri, N. and Fausto, N. 1991. Oval cell proliferation and the origin of small hepatocytes in liver injury induced by D-galactosamine. Am. J. Pathol. 139: 535-552.

10. Novikoff, P. M., Ikeda, T., Hixson, D. C. and Yam, A. 1991. Characterizations of and interactions between bile ductule cells and hepatocytes in early stages of rat hepatocarcinogenesis induced by ethionine. Am. J. Pathol. 139: 1351-1368.

11. Pack, R., Heck, R., Dienes, H. P., Oesch, F. and Steinberg, P. 1993. Isolation, biochemical characterization, long-term culture and phenotype modulation of oval cells from carcinogenfed rats. Exp. Cell Res. 204: 198-209.

12. Rutenberg, A. M., Kim, H., Fischbein, J. W., Hanker, J. S., Wasserkrug, H. L. and Seligman, A. M. 1969. Histochemical and ultrastructural demonstration of gamma-glutamyltranspeptidase activity. J. Histochem. Cytochem. 17: 517-526.

13. Sarraf, C., Lalani, E-N, Golding, M., Anikumar, T. V., Poulsom, R. and Alison, M. 1994. Cell behavior in the acetylaminofluorene-treated regenerating rat liver. Am. J. Pathol. 145: 1114-1126.

14. Sell, S. 1983. Comparison of oval cells induced in rat liver by feeding N-2-fluorenylacetamide in a choline-devoid diet and bile duct cells induced by feeding 4,4'-diaminodiphenylmethane. Cancer Res. 43: 1761-1767.
15. Sell, S. and Dunsford, H. A. 1989. Evidence of the stem cell origin of hepatocellular carcinoma and cholangiocarcinoma. Am. J. Pathol. 134: 1347-1363.

16. Sell, S. and Pierce, G. B. 1994. Maturation arrest of stem cell differentiation is a common pathway for the cellular origin of teratocarcinomas and epithelial cancers. Lab. Invest. 70: 6-22.

17. Sell, S. and Salman, J. 1984. Light and electron microscopic autoradiographic analysis of proliferating cells during the early stages of chemical hepatocarcinogenesis in the rat induced by feeding N-2-fluorenylacetamide in a choline-deficient diet. Am. J. Pathol. 114: 287-300.

18. Sells, M. A., Katyal, S. L., Shinozuka, H., Estes, L. W., Sell, S. and Lombardi, B. 1981. Isolation of oval cells and transitional cells from the livers of rats fed the carcinogen DL-ethionine. $J$. Natl.Cancer Inst. 66: 355-362.

19. Sirica, A. E. and Cihla, H. P. 1984. Isolation and partial characterizations of oval and hyperplastic bile ductular cell-enriched populations from the livers of carcinogen and noncarcinogentreated rats. Cancer Res. 44: 3454-3466.

20. Sirica, A. E., Mathis, G. A., Sano, N. and Elmore, L. W. 1990. Isolation, culture and transplantation of intrahepatic biliary epithelial cells and oval cells. Pathobiology 58: 44-64.

21. Sirica, A. E., Sattler, C. A. and Cihla, H. P. 1985. Characterization of a primary bile ductular cell culture from the livers of rats during extrahepatic cholestasis. Am. J. Pathol. 120: 67-78.

22. Steinberg, P., Steinbrecher, R., Radaeva, S., Schirmacher, P., Dienes, H. P., Oesch, F. and Bannasch, P. 1994. Oval cell lines OC/CDE 6 and OC/CDE 22 give rise to cholangiocellular and undifferentiated carcinomas after transformation. Lab. Invest. 71: 700-709.

23. Tee, L. B. G., Kirilak, Y., Huang, W.-H., Morgan, R. H. and Yeoh, G. C. T. 1994. Differentiation of oval cells into duct-like cells in preneoplastic liver of rats placed on a choline-deficient diet supplemented with ethionine. Carcinogenesis 15: $2747-$ 2756.

24. Tsao, M. S. and Grisham, J. W. 1987. Hepatocarcinomas, cholangiocarcinomas, and hepatoblastomas produced by chemically transformed cultured rat liver epithelial cells. Am. $J$. Pathol. 127: 168-181.

25. Yaswen, P., Hayner, N. T. and Fausto, N. 1984. Isolation of oval cells by centrifugal elutriation and comparison with other cell types purified from normal and preneoplastic livers. Cancer Res. 44: 324-331.

26. Yoon, B.-I., Lee, J.-H., Joo, K.-W., Lee, Y.-S. and Kim, D.-Y. 2000. Isolation of oval cells from hamster treated with diethylnitrosamine and 2-acetylaminofluorene. J. Vet. Med. Sci. 62: 255-261.

27. Yoshimura, H., Harris, R., Yokoyama, S., Takahashi, S., Sells, M. A., Pan, S. F. and Lombardi, B. 1983. Anaplastic carcinoma in nude mice and in original donor strain rats inoculated with cultured oval cells. Am. J. Pathol. 110: 322-332. 